\title{
PROBLEMATIKA RAZVOJA MEST IN SPREMINJANJA RABE MESTNEGA PROSTORA
}

\author{
Mirko Pak*, Angelca Rus** \\ * Pod vrbami I, I000 Ljubljana \\ e-mail: mirko.pak@guest.arnes.si \\ ** Mestna občina Ljubljana, Oddelek za urbanizem in okolje, \\ Poljanska cesta 28, Ljubljana \\ e-mail: angelca.rus@lj.si
}

Izvirni znanstveni članek

COBISS 1.01

\section{Izvleček}

Nagla rast mest prinaša velike spremembe v rabo njihovega prostora. Ob temeljnih ekonomskih so glavni razvojni dejavnikih še tehnologija, demografska gibanja, politika, socialna zgradba, kultura in globalizacija. Mesto postaja vse bolj pester prostor. V osnovi se to kaže v naglem porastu povpraševanj po gradbenih dovoljenjih in po informacijah glede posegov v prostor ter v različnih problemih med planirano rabo in željami investitorjev.

Ključne besede: razvoj mest, planiranje, globalizacija, raba prostora, Ljubljana.

\section{PROBLEMS OF URBAN DEVELOPMENT AND OF CHANGING OF THE URBAN LAND USE}

\begin{abstract}
Rapid growth of cities causes significant changes in the use of their space. Besides basic economic development factors, the principal development factors are technology, demographic trends, policy, social structure, culture and globalisation. City is becoming an increasingly heterogeneous space. Basically, this is indicated by rapid increase in the demand for construction permits and for information as regards the activities, which affect the environment, as well as by a number of problems arising in association with the planned use and investitors' desires.
\end{abstract}

Key words: development of cities, planning, globalisation, use of physical space, Ljubljana. 


\section{UVOD}

Koncentrični, linearni, zonalni, kombinirani in drugi klasični modeli razvoja in zgradbe mest prejšnjih stoletij, doživljajo povsem nov in pospešen razvoj, ki se z velikostjo mesta stopnjuje. Ekonomske spremembe $\mathrm{v}$ najširšem pomenu, vključno $\mathrm{z}$ vedno pomembnejšim in bolj izpostavljenim vplivom (procesom) globalizacije narekujejo tako prostorske, kot strukturno - funkcijske in socialne spremembe. V vseh okoljih, bolj ali manj razvitih, ima ta razvojni proces tako makro kot mezo ter mikro vzroke in posledice ter razsežnosti. Zato sta globalizacija in lokalizacija osnova globalne perspektive $\mathrm{v}$ razumevanju kompleksnosti urbanega prostora (Pacione, 2002). Zaradi samega značaja objekta obravnave - mesta, predmeta stroke in kompleksnosti ter soodvisnosti je to po strokovni plati osrednja in tudi v meddisciplinarnem pogledu težiščna geografska problematika. Vedno več literature s področja urbane geografije se zato ukvarja $\mathrm{z}$ recentnim razvojem in preobrazbo mest. To je mogoče zaslediti tudi na vsakoletnih znanstvenih srečanjih Komisije za urbano geografijo Mednarodne geografske zveze in je še posebej močno prisotno v zbornikih zadnjih dveh srečanj, Cities in Transition, 2004 in Changing Cities - International Perspectives, 2004.

Za osnovne dejavnike recentnega razvoja mest navedimo naslednje:

Nedvomno ima ekonomija prevladujoč vpliv na urbani razvoj, na nove oblike mest in nove elemente rabe mestnega prostora. Kaj se bo proizvajalo, kje se bo kaj proizvajalo in kako se bo proizvajalo naj bi bila gospodarska osnova rasti in razvoja mest, pri čemer ni mišljena le proizvodnja kot takšna, temveč tudi ves terciarni sektor kot sestavni del kompleksnega ekonomskega področja.

Kot posledica ekonomskih sprememb vpliva tehnologija na urbane oblike (morfologijo v najširšem pomenu). S prometnim razvojem vpliva na suburbanizacijo, pa tudi na vrsto sprememb v rabi, strukturi in izgledu mesta. Dober primer za to je množična preobrazba obsežnih predelov v rečnih in obmorskih pristaniščih, kjer je vrsta novih funkcij, vključno z bivalno, nadomestila nekdanjo rabo za potrebe pristaniškega prometa, kot na primer Londonski doki, frankfurtsko pristanišče ob Majni in drugod.

Demografske spremembe vključujejo selitve prebivalstva, socialno zgradbo in s tem povezan izgled mestnih predelov. Na splošno se gostota prebivalstva v mestih zmanjšuje, še posebej $\mathrm{v}$ mestnih središčih, $\mathrm{v}$ malih mestih tudi na račun velikih mest.Zato je problematika selitev večinoma pomembnejša od problematike naravnega prirastka. Na tem področju so še posebej v ospredju vprašnja deurbanizacije, reurbanizacije in suburbanizacije.

Na razvoj mest največkrat pomembno vpliva tudi politika. To je še posebej spremljalo razvoj mest v socialističnih državah, kjer v preteklosti in bilo dosti razumevanja za prostorske posledice urbanega razvoja. Poseben vpliv na razvoj je imela prostorska organizacija infrastrukture, še večje posledice pa je zapustila gradnja velikih blokovskih četrti, katerih velik del danes doživlja krizo in hkrati s tem povezano živahno preobrazbo. Ena največjih tovrstnih blokovskih četrti Grünau v Leipzigu se tudi zaradi splošnih ekonomskih problemov mesta kljub vsem prizadevanjem in vlaganjem ne more ustrezno razvijati. Predeli tako imenovanih socialnih blokov (stanovanjskih četrti) so v krizi tudi v večini mest razvitih evropskih držav, sicer se pa zelo različno razvijajo glede na današnje ekonomsko stanje njihovega prebivalstva. 
Znana je tudi problematika bivših industrijskih središč. Politične odločitve in usmeritve vplivajo tudi na ekonomsko bazo mest.

Na razvoj in strukturo mest vplivata njihova socialna zgradba in družbeno okolje.

Zanemarljiv ni vpliv kulture, ki še posebej izstopa v starih mestnih jedrih, pa tudi v razvoju postmodernističnih mest samih. Podobno velja za $\mathrm{v}$ kulturne funkcije določenih mestnih predelov.

Proces globalizacije se v geografskih analizah zrcali v treh vidikih : demografskem, političnem (politično-ekonomskem) in kulturnem. Pri tem je treba izpostaviti selektivnost tako domačega kot tujega kapitala. Kot integralni del globalizacije pa se v geografiji izpostavlja ekološka problematika razvoja mest. (Pacione, 2004)

\section{URBANIZACIJSKI PROCESI}

Značilnost današnjega razvoja mest je, da hkrati dokaj enakovredno sodelujejo vsi urbanizacijski procesi, ki vsi vodijo $\mathrm{k}$ dekoncentraciji prebivalstva, $\mathrm{h}$ koncentraciji delovnih mest ob njihovi hkratni suburbanizaciji ter h koncentraciji dohodka. Vse to je že značilno tudi za Ljubljansko urbano aglomeracijo (Ravbar, 2002). Lep tovrsten primer je Münchenska aglomeracija, kjer je v obdobju 1970-1085 prebivalstvo poraslo za 10,5\%, delovna mesta za 47,5\% in dohodek za 46,6\%. V "kriznem" Severnem Porenju je bil proces bistveno drugačen, saj je prebivalstvo naraslo le za $6,3 \%$, delovna mesta za $20,1 \%$ in dohodek na prebivalca za $32 \%$. Takšne razlike v razvoju mest so posledica splošnih razvojnih razlik v vseh okoljih in so $\mathrm{v}$ prid razvoja velikih mest ter gospodarsko močnejšim mestnim aglomeracijam.

Raba mestnega prostora je $\mathrm{z}$ naglim razvojem mest vključno s prenovo mestnih središč in vse pogosteje tudi drugih predelov mestnega središča, pa tudi širšega mestnega teritorija, vedno bolj raznolika, pestra in pomešana. Čim hitrejši ta razvoj je, tem bolj pestra je raba mestnega prostora, kar še posebej izstopa pri velemestih (Mookherjee, Hoerauf, 2004). Pogoste koncentracije številnih, tudi novih dejavnosti se razen na obrobju mest, v nemški literaturi za tovrstne koncentracije uporabljajo termin Speckgürtel (Kinkel, 2000), vse pogosteje javljajo tudi v drugih delih mest. V večjih mestih so pogosta nova, največkrat lokalna oskrbna središča (Aguilar, 2004). V Zagrebu se predel ob železniškem kolodvoru spreminja v več funkcionalno središče, seveda z vsemi prometnimi problemi (Sić, 2004). Marsikje pa stare trgovske ulice (ceste) s prenovo spreminjajo, oziroma prilagajajo spremenjenim socialnim, funkcijskim, funkcionalnim ali celo ekološkim potrebam njihovega ožjega in nemalokrat tudi širšega okolja.

Nagla rast in razvoj mest prinašata bistvene spremembe tudi $\mathrm{v}$ kvaliteto življenja. Večinoma so raziskave pokazale izboljšanje kvalitete okolja zaradi zmanjšanja vpliva motečih dejavnikov (emisije, hrup itd) in z izboljšanjem infrastrukture. Na drugi strani pa pestrejša raba mestnega prostora, nekontrolirana koncentracije in mešanje neustreznih dejavnosti tudi s stanovanjsko funkcijo, vse prej kot pozitivno vpliva na kvaliteto življenjskega okolja in posameznih mestnih predelov na sploh. Ali razne moteče dejavnosti, vključno s povečanim prometom, ki se vse pogosteje kopičijo okrog "elitnega stanovanjskega" naselja Murgle, ne znižujejo njegovo bivalno vrednost? Anketiranje je takšen proces in s tem seveda vse posledice, 
od zmanjšanja vrednosti prostora in stavb naprej, že pokazalo (Pak, 2003 in 2004). Zlasti pa so mnoge lokalne ceste postale povezava med mestom in rastočimi suburbaniziranimi območji. Spreminjajo se pogoji bivanja glede na okolje, dostopnost in drug (Braun, 2004). Podobni procesi izstopajo $\mathrm{v}$ hitro rastočih mestih $\mathrm{v}$ nekdanjih socialističnih državah, kjer kvaliteta Življenja ne more slediti naglemu razvoju mest (Nistor, 2004).

Glede na to, da se zlasti manjša mesta razvijajo v odvisnosti od gospodarske razvitosti in usmerjenosti širše regije, naj bi v njihovem razvoju izstopala tudi naslednja razvojna vprašanja : pogostejše kratkoročne investicije na lokalni in regionalni ravni; povečane razdalje za opravljanje proizvodnih procesov, kar bi vodilo $\mathrm{k}$ večji pestrosti rabe prostora; povečana individualna mobilnost zaradi zahtevnejše produkcije in višje tehnologije.

Takšen razvoj evropskih mest Venturi opredeljuje znaslednjimi procesnimi spremembami $\mathrm{v}$ primerjavi z njihovim preteklim razvojem: zgoščenost - zredčenost, koncentrirano dekoncentrirano, kontinuirano - diskontinuirano, centripetalno - centrifugalno, simetrično - asimetrično, stabilno - spremenljivo (Venturi, 2002).

Tudi raba prostora $\mathrm{v}$ slovenskih mestih sledi prostorskemu razvoju tujih mest, kar vodi $\mathrm{k}$ večji heterogenosti rabe, znatno spreminja vrednost zemljišč in stavb, vpliva na sam izgled in sestavo mest ter na kvaliteto življenja v njih. Drozg (2004) ugotavlja za Maribor vse močnejše mešanje stanovanjske $\mathrm{z}$ drugimi funkcijami in označuje terciarizacijo sicer v prvi vrsti za ekonomski proces, ob tem pa tudi za pomemben prostorski proces. Pomen urbane središčnosti dokaj hitro izgublja svoj nekdanji pomen. Naglo rastoča nakupna središča pritegnejo vrsto funkcij, ki so bile v preteklosti domena mestnega središča. V ljubljanskem mestnem središču in podobno velja tudi za Maribor ter še katero slovensko mestno središče, je zaradi tega trgovska funkcija močno prizadeta . Ta še dalje nazadujejo $\mathrm{v}$ primerjavi z velikimi oskrbnimi središči na mestnem obrobju (Pak, 2004). V Ljubljani so posamezni deli mestnega središča svojo trgovsko funkcijo močno osiromašili, kar še posebej velja za širše območje mestnega predela Ajdovščina.

Po nekaterih ocenah naj bi bilo v Ljubljani, kljub velikemu povpraševanju, dovolj zazidljivih površin, ob tem ko cena še naprej raste. Posebej je pozidava usmerjena $\mathrm{v}$ širše območje mestnega središča, kamor je lociranih tudi večina najpomembnejših projektov od postajnega centra do Barjanske ceste. Opozoriti velja, da je da je planska in načrtovalska podstat prostorskih rezervatov in namembnostnih opredelitev $\mathrm{v}$ danih tržnih razmerah lahko le prehodna in časovno omejena (Bežan, 2001). Vse več je polifunkcionale pozidave, ki je seveda takšna tudi z morfološkega vidika. To pa že zadeva vprašanje skladnosti odprtega prostora. Mnogokrat nova stanovanjska in nestanovanjska gradnja nista v skladu z obstoječo fiziognomijo ulice ali predela, ki je javni prostor (skupna last) in naj bi bila tudi skupna skrb vesh uporabnikov prostora, ne pa parcialnih interesov. Najnovejši urbanizacijski procesi pa močno spreminjajo tudi socialno sestavo posameznih mestnih predelov. Z vsem naštetim je povezana kakovost bivanja $\mathrm{z}$ vzpostavljanjem urbanih prednosti na vseh površinah, ki to omogočajo. Kako to uveljaviti ob poveličevanju zasebne lastnine? Kakšna je danes sploh lahko kakovostna urbana površina se sprašuje Lobnik (2002).

Pri nas vsa ta "tranzicijska" vprašanja urbanizacije izstopajo še posebej v Ljubljani. Kažejo se v njenem celotnem strukturnem v najširšem pomenu in v prostorskem razvoju, ki se ne nazadnje kaže tudi v povpraševanju po za gradnjo primernih zemljiščih. 


\section{NEKATERE ZNAČILNOSTI DOSEDANJEGA PROSTORSKEGA IN DEMOGRAFSKEGA RAZVOJA LJUBLJANE}

$\mathrm{V}$ povojnem obdobju smo priča izredno hitremu prostorskemu širjenju Ljubljane. Še leta 1953 je živelo v Ljubljani, ki je obsegala mestno središče in predmestja: Trnovo, Dolenjsko predmestje, Moste, Bežigrad, Zgornja Šiška 154.700 prebivalcev; leta 1981 ko se meja mesta pomakne močno navzven, v Šiški vse do Šentvida, za Bežigradom do Črnuč, v Mostah do Polja 253.000, leta 1991 pa v približno enakih mejah 267.008 (Rus,Stanič, 1993).

V tem obdobju so se v Ljubljani povečale poseljene površine kar za sedemkrat, zlasti $\mathrm{v}$ fazi intenzivne industrializacije. Za tako veliko povečanje poselitvenih površin je razlog tudi v neučinkovitem nadzoru nad prostorskim razvojem mesta. V šestdesetih letih, v edinem obdobju, za katero obstajajo podatki, so na primer eno polovico stanovanjskih hiš zgradili na območjih, ki niso bila predvidena za stanovanjsko gradnjo, torej brez načrtovanega razvoja (Strategija, 2002).

Po podatkih registra prebivalstva (Statistični letopis Ljubljana 2004) beležimo v Mestni občini Ljubljana v zadnjem desetletju upadanje števila prebivalstva od 263.4191 .1995 na 257.933 1.2003. Vedno slabša starostna struktura prebivalcev in s tem povezano staranje prebivalstva, so eden od vzrokov, da se ti trendi še nadaljujejo. Po letu 2000 ima Ljubljana negativni naravni prirastek. Zaustavlja se tudi priseljevanje iz drugih slovenskih občin, priseljevanja iz drugih republik nekdanje Jugoslavije pa praktično ni več. Posledica tega je zniževanje deleža aktivnega prebivalstva in porast vzdrževanega prebivalstva.

V praksi se je izkazalo, da je Dolgoročni plan Ljubljane iz 1. 1986 v marsičem temeljil na neuresničljivih domnevah. Tako je npr. na podlagi trendov naravne in selitvene rasti narejena demografska napoved predvidevala, da bo število prebivalcev 1. 2001 naraslo na okoli 400.000, dejansko pa se je to število ustavilo pri komaj 260.000 prebivalcih. Glede na precenjen obseg demografske rasti so bile temu primerno prilagojene tudi razvojne površine mesta.

$\mathrm{Z}$ osamosvojitvijo Slovenije je prišlo do spremembe mnogih zakonov. Ukinjen je bil sistem družbenega planiranja, začeli sta se privatizacija in denacionalizacija. Občina je s tem izgubila precej možnosti neposrednega vplivanja na dogajanje v prostoru. Po praktično 15 država še ni ponudila celovitih instrumentov kakovostnega usmerjanja prostorskega razvoja in učinkovitejšega uveljavljanja javnega interesa. Slovenija je tudi v fazi prilagajanja evropski zakonodaji.

Resnična raba prostora se težko prilagaja namenski rabi prostora, ki jo plan določa kot dopustno in zaželeno. Problem je v tem, da planske določbe vplivajo na rabo prostora le takrat, ko investitor namerava izvesti poseg. $\mathrm{V}$ povezavi $\mathrm{z}$ načrtovanimi posegi je treba ravnati $\mathrm{v}$ skladu s planom oziroma prostorskimi ureditvenimi pogoji (PUP). Resen problem so primeri, ko v posameznih območjih ni interesa za izvedbo posega, zaradi česar se tako območje ne razvija v skladu s planom. Nemalokrat se celo degradira. Podoben, če ne še večji problem nastane, ko hoče investitor doseči želeno rabo na tistem zemljišču, ki si ga je izbral. Zaradi pomanjkanja ponudbe alternativnih lokacij lahko v takem primeru nastanejo resne zadrege, na primer odvračanje investitorjev ali pritiski za dosego spremembe namembnosti v planu (Prostorska zasnova, 2002). 
Mestni svet MOL je 1.2002 sprejel gradivo prostorske zasnove Mestne občine Ljubljana, ki pripisuje velik pomen prihodnjemu prostorskemu razvoju in je kot konceptualno gradivo z izrazito usmeritveno naravo, ki bo služil za izdelavo dokumenta prostorskega razvoja MOL.

Prostorska zasnova daje poudarek možnosti prepletanja različnih rab ob upoštevanju meril nemotečega sožitja. Končni cilj prostorskega planiranja je usmerjanje sedanjega stanja prostorskega razvoja $\mathrm{v}$ novo, ciljno, planirano ureditev.

V zasnovi so izpostavljene naslednje kategorije območij, ki bodo podrobneje opredeljena $\mathrm{V}$ novem planskem dokumentu:

- območja mešane rabe ob vpadnicah v mesto, intenzivneje ob stičiščih z obvoznim oziroma avtocestnim sistemom

- stanovanjska območja, predvsem raščena območja, pa tudi nekatere stanovanjske soseske uvršča med mešane rabe, kjer sicer prevladujejo stanovanja in dejavnosti osnovne oskrbe, lahko pa se pojavijo tudi poslovne dejavnosti in manjši storitveni obrati.

- Predvidena je nova kategorija čistih stanovanjskih območij.

- Posebej je izpostavljena kategorija trgovskih središč, ki naj bi veljala le za območji BTC in Rudnik.

- Na obstoječe proizvodne površine se bodo lahko naselile tudi druge vrste rabe, ki bodo skladne s proizvodnjo.

- Posebej so izpostavljena parkovne in rekreacijske površine

Dodatno težavo pa so v planiranju v zadnjih letih povzročali postopki denacionalizacije ter še vedno nedelovanje trga na področju zemljiške politike v smislu ponudbe in povpraševanja.

Trenutne razmere $\mathrm{v}$ Ljubljani na področju prostorskega načrtovanja samo potrjujejo razmišljanja o tem, da bo potrebno čimprej pripraviti nove občinske prostorske akte v skladu z določili Zakona o urejanju prostora (ZUreP-1, 2002). Eden od dokumentov je Strategija prostorskega razvoja občine, ki bo določila usmeritve za razvoj dejavnosti v prostoru tako, da bodo zagotovljeni pogoji za vzdržen in usklajen razvoj na območju občine. Natančnejšo razdelavo strategije prostorskega razvoja bo določala urbanistična oziroma krajinska zasnova. $\mathrm{Na}$ drugi strani pa je potrebno pripraviti in sprejeti temeljni izvedbeni prostorski akt občine, to je prostorski red, s katerim se določa območja namenske rabe prostora, pogoje in merila ter ukrepe za načrtovanje v prostoru. Obenem je prostorski red tudi podlaga za pripravo občinskih lokacijskih načrtov.

\section{VLOGE ZA IZDAJO MNENJ GLEDE POSEGOV V PROSTOR}

Občina je dolžna po Zakonu o urejanju prostora dajati mnenja za različne posege v prostor od informacij o namembnosti zemljišč do urbanističnih oziroma lokacijskih informacij. Pristojen občinski organ je na zahtevo vlagatelja dolžan posredovati odgovor na vlogo, kot so npr. podatki o namenski rabi prostora, podatki o območjih varovanj in omejitev, vrstah dopustnih dejavnosti, vrstah dopustnih gradenj in drugih del ter vrste dopustnih objektov glede na namen. Zainteresirani se zanimajo za informacije iz različnih razlogov, bodisi da bodo zemljišče z določenim namenom kupili ali prodali, ali pa želijo priti do gradbenega dovoljenja. 
V zadnjih petih letih je bilo največ vlog za parcele v območju katastrskih občin Trnovsko in Karlovško predmestje, Moste, Bežigrad in Dravelje. Leta 2004 so s preko 2000 vlogami izstopale K.O. Vič, Karlovško predmestje, Dravlje in Moste. Velik interes po različnih informacijah in mnenjih (karta 1) kaže na to, da je v Ljubljani še veliko nepozidanih parcel. Te so bile v preteklosti s posebnimi dokumenti rezervirane za znane investitorje (npr. Regulacijski zazidalni načrt iz leta 1969) ali pa so danes denacionalizirana in imajo lastniki interes zanje čim več iztržiti. Še vedno je največ zanimanja za parcele za individualno stanovanjsko gradnjo, zlasti po t.im."vila objektih".

Po drugi strani pa je v mestu vrsta degradiranih območij, ki nimajo jasno opredeljene vsebinske funkcije. Taki primeri so npr:: v conah okrog Saturnusa, Teola v Mostah ali Totra nasproti fužinskega gradu. Mnogokrat trg prehiti pripravo planskih dokumentov in zgodi se, da lastniki prodajajo svoja zemljišča, ki nimajo vsebinske funkcije ali so povsem v konfliktu z obstoječo infrastrukturo (npr. betonarna). Število vlog se vedno bolj povečuje, saj je bilo samo v letu 2004 na Oddelku za urbanizem MOL izdanih 40.380 mnenj. To pomeni, da je bilo potrebno izdati okoli 170 odgovorov na dan. Sem pa niso štete vmesne faze obdelave vloge, kot so vračanje vlog v dopolnitev, vročenja vlagatelju in ponovna obdelava. Sicer pa je bila dinamika od leta 1997, ko se tudi elektronsko spremljajo prispele vloge, dinamika dajanje odgovorov oziroma izdajanje mnenj naslednja:

\begin{tabular}{|l|r|r|r|r|r|r|r|r|}
\hline Leto & 1997 & 1998 & 1999 & 2000 & 2001 & 2002 & 2003 & 2004 \\
\hline Število vlog & 8.953 & 15.687 & 16.820 & 16.434 & 14.744 & 31.445 & 40.440 & 40.380 \\
Indeks & 100 & 175 & 188 & 183 & 165 & 351 & 452 & 451 \\
\hline
\end{tabular}

Znatno povečanje števila vlog gre tudi na račun pomanjkljivo izpolnjenih obrazcev ali pomanjkljive dokumentacije, ki se vrne v dopolnitev vlagatelju. Preko 40.000 vloženih vlog kaže na velik interes po zemljiščih .

\section{IZDAJA GRADBENIH DOVOLJENJ}

O številu izdanih gradbenih dovoljenj v Ljubljani v posameznih letih, ni povsem točnih podatkov. Arhiv namreč ni bil centralno voden, ampak po posameznih upravnih enotah. Še najbolj sprejemljiv je podatek, ki ga zbira Statistični urad RS z obrazcem GRAD-PGD/M in GRAD-PUD/M. Posegi so v tem obrazcu klasificirani po Enotni klasifikaciji vrst objektov, CC-SI (UL RS št.33/03) in so razvrščeni v dve glavni skupini: stanovanjske in nestanovanjske stavbe, te pa se delijo na nadaljnjih 32 podskupin. Objekte smo združili v 10 smiselnih skupin in analizirali število gradbenih dovoljenj, izdanih v obdobju 1998 do 2004. Največ izdanih dovoljenj je bilo na območju K.O. Trnovsko predmestje (117), Bizovik (78), Zgornja Šiška (87), Kašelj, Dravlje, Vižmarje in Zadobrova (57). Več kot dve tretjini dovoljenj je bilo izdanih za stanovanjske objekte, tri četrtine za enostanovanjske stavbe. V teh območjih je bilo tudi največ zanimanja za gradnjo večstanovanjskih stavb.

Takoj za stanovanjskimi objekti je bilo največ izdanih dovoljenj za gradnjo upravnih in pisarniških stavb. Koncentracija teh je največja v ožjem mestnem središču. Dovoljenj za 


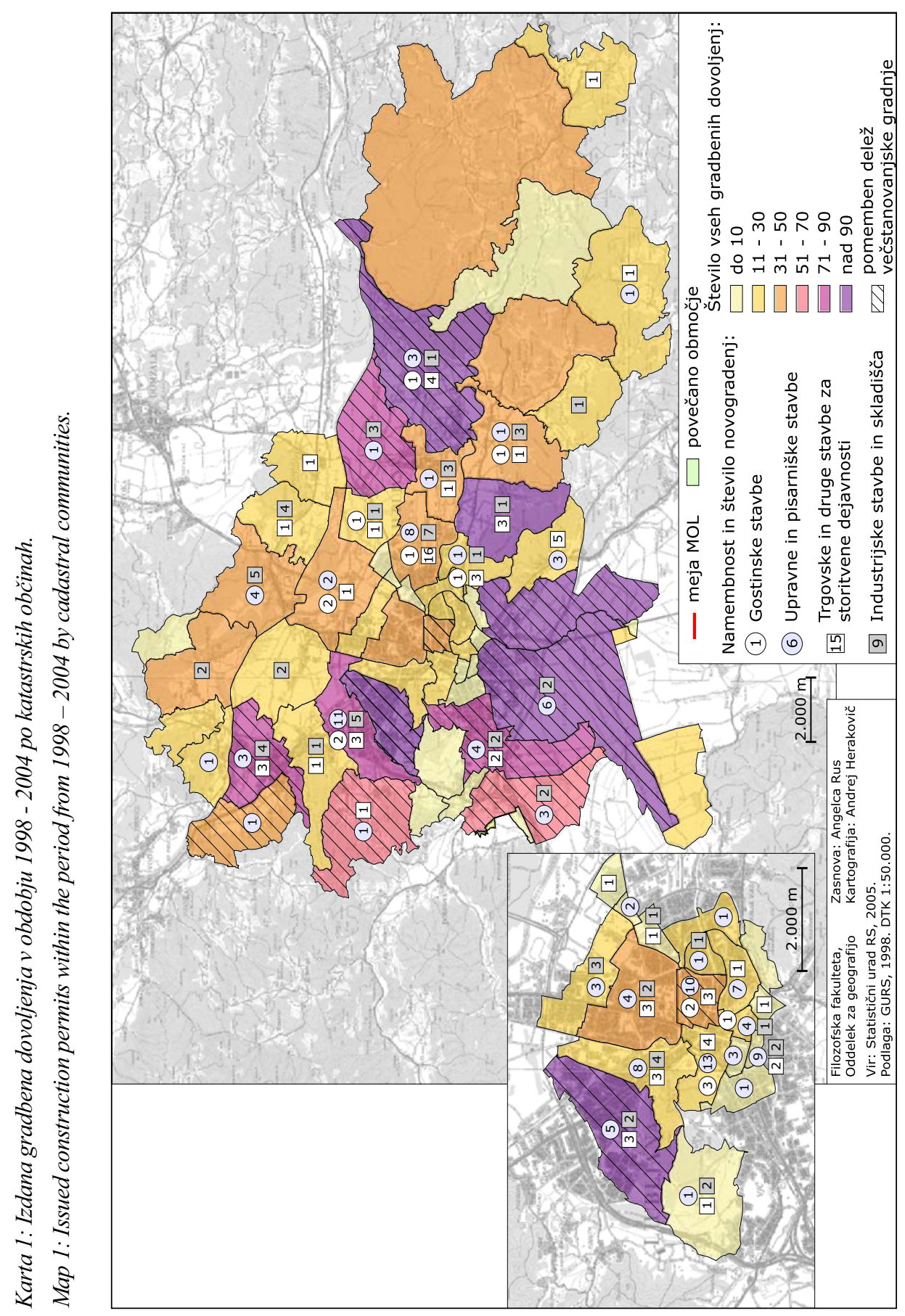




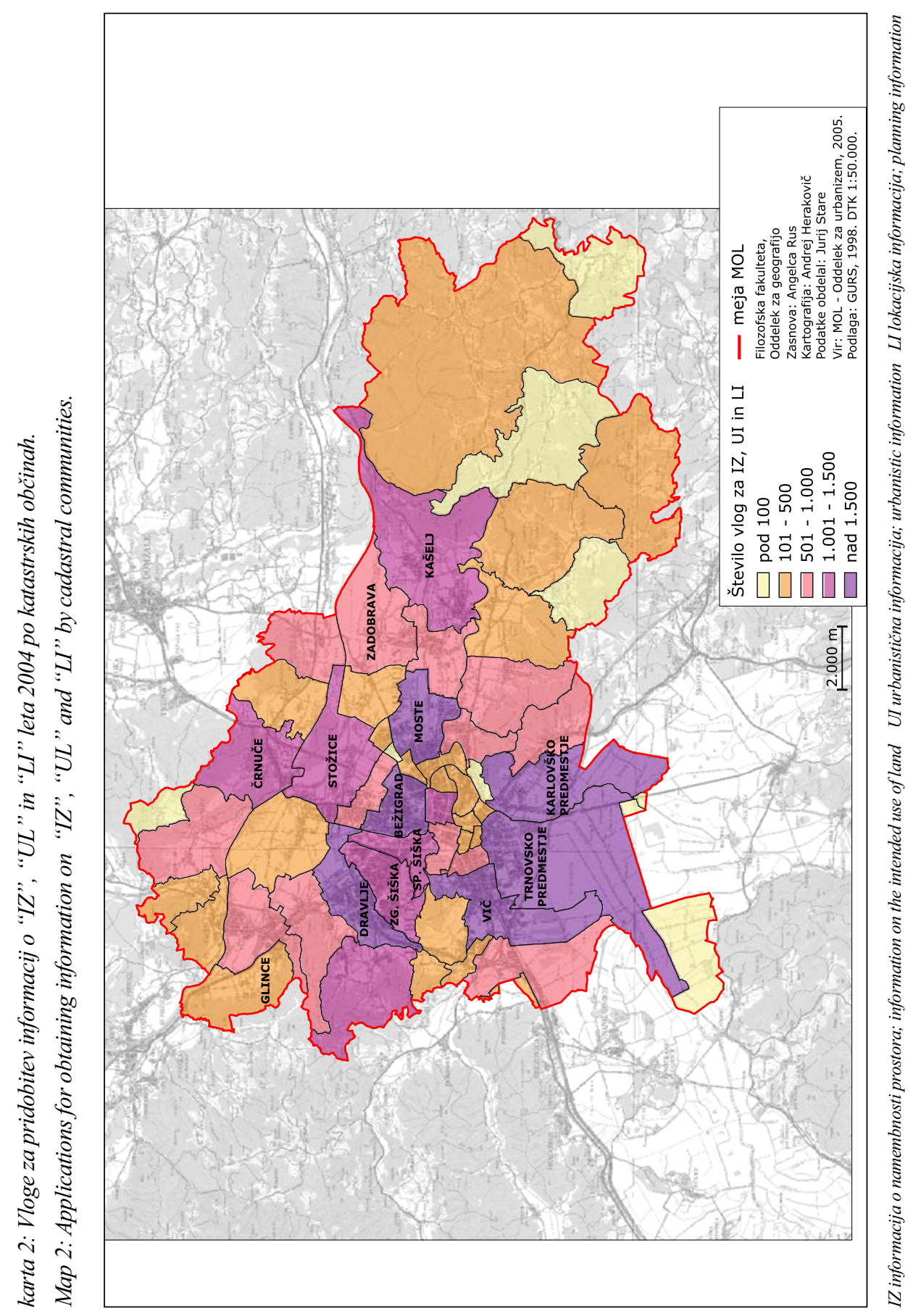


trgovske in druge stavbe za storitvene dejavnosti je bilo izdanih zdaleč največ v K.O. Moste, na območju današnjega BTC.

\section{SKLEP}

Velik pritisk na zazidljive površine ustvarja v Ljubljani neskladje med izvajanjem urbanističnega načrta in realnostjo. Raba mestnega prostora je vedno bolj heterogena tako v funkcijskem, morfološkem in socialnem pogledu. Izredno visoke in še nadalje rastoče cene zemljišč in gradnje to heterogenost še povečujejo. Poglablja se socialne segregacija, pri čemer "slamizacijo" starih blokov zavira veliko povpraševanje po stanovanjih. Neznani tudi niso pojavi prehitevanja investitorjev in špekulacij s prostorom. Slednje se kaže pogosto tudi v primeru denacionalizacijskih upravičencev. Med probleme sodi tudi mestna infrastruktura.

Številne nove in raznolike dejavnosti niso namenjene lokalnemu prebivalstvu ampak širšega mestnega ali celo izvenmestnega prostora. Poleg rasti velikih nakupnih središč na mestnem obrobju nastaja še veliko število manjših koncentracij različnih dejavnosti, torej nekakšnih sekundarnih središč. Med te štejemo lahko tudi manjša nakupna središča oskrbnega značaja in posamezne velike nakupne objekte, ki zaradi vedno močnejše konkurence, doživljajo zelo različne razvojne trende. Vse skupaj pa vodi v vedno močnejše mešanje rabe prostora, ki je marsikdaj s funkcionalnega vidika, z vidika kvalitete bivalnega okolja in tudi z vidika smotrnega razvoja mestnega teritorija, vprašljivo. Podobno se dogaja v obmestju, kjer se vse bolj pojavlja prostorsko povezana suburbanizacija bivanja in delovnih mest.

Trendi razvoja Ljubljane v zadnjem desetletju kažejo veliko tendenco širjenja navzven, torej na območja, kjer so površine za novogradnje še na voljo. Funkcijsko območje Ljubljane presega statistično območje mesta, kakor rudi upravno administrativno mejo občine. Nova pozidava se širi neposredno na rob sosednjih občin. Gre za močno funkcijsko prepletanje z okoliškimi občinami, zlasti na področju komunalnega urejanja, energetike, mestnega in primestnega potniškega prometa ter izrazito dnevne delovne in šolske migracije. V fazi priprave novih prostorskih planskih dokumentov se občina tega stanja posebej zaveda. Izhodišča programske zasnove MOL slonijo na konceptu, da se mesto načeloma ne bi širilo navzven, temveč da se zagotovijo površine znotraj zazidanih območij. Morfološki model naj bi se širil v krakih vzdolž osnovnih prometnih osi, kjer naj bi ta območja sčasoma dobila prepoznavna vsebinska jedra s stanovanjskimi, poslovnimi in javnimi objekti ter urejenimi zelenimi površinami.

V prihodnje se bodo morali spremeniti tudi urbanistični pogoji (namenska raba prostora in tipi objektov, gradbene linije itd), ki naj bi veljali za celotno mesto.

Ena ključnih nalog bodočega razvoja bo omejitev osebnega prometa $\mathrm{z}$ razvijanjem privlačnega javnega potniškega prometa (mestna železnica, uvedba prestopnih točk, dopolnitev cestnega omrežja itd). Priprava novih planskih dokumentov (prostorski red občine in občinski lokacijski načrt) bodo vsekakor dobra podlaga za drugačno načrtovanje in regulacijo posegov v prostor. Za reševanje problemov v širšem prostoru pa je potrebno čim prej pripraviti regionalni prostorski planski akt. Pravna podlaga za sprejem takšnega dokumenta je v veljavnem zakonu o urejanju prostora. 


\section{Literatura}

Aquilar, A., G., 2004: Globalization and the Restructuring of Urban Space in Mexico City. Changing Cities - International Perspectives. Glasgow, s. 65 - 77.

Bežan, M., 2001: Pogojenost preobrazbe mesta in pokrajine. Pogledi na Ljubljano, Ljubljana, s. $9-18$.

Braun, G., 2004: The Impact of State Interventions on Urban Structure. Changing Cities Interantional Perspectives, Glasgow, s. $173-183$.

Drozg, V., 2004: Spatial Development of Slovenian Towns in the Last Decade. Cities in Transtiition, Dela 21, Ljubljana, s. $121-130$.

Lobnik, U., 2002: Strnjeni razvoj - ranljivost urbanega. Urbani Izzivi 2002, 1. 13, 2, Ljubljana, s. $11-19$.

Mookherjee, D., Hoerauf, E., 2004: Exploration and Measurement of Sprawl in the Delhi Urban Agglomeration. Changing Cities - Interantional Perspectives, Glasgow, s. 247 -252 .

Nistor, M., M., 2004: Monitoring the Cities of Tomorrow: The Intra - Urban Development of Post - Socialist Cities. Changing Cities - International Perspectives, Glasgow, s.207 -216 .

Pacione, M., 2004: Changing Cities: A Global Perspective. Changing Cities - Interantional Perspectives, Glasgow, s. $2-35$.

Pak, M., 2002: Mesto na prehodu. Geografija in njene aplikativne možnosti, Dela 18, Ljubljana, s. $345-448$.

Pak, M., 2002: Funkcijska zgradba. Geografija Ljubljane, Ljubljana, s. 53 - 58.

Pak, M., 2004, Problematic of the Functional Structure of Slovene Cities. Cities in Transition, Dela 21, Ljubljana, s. $131-138$.

Ravbar, M., 2002: Suburbanizacijske težnje v razvoju prebivalstva in delovnih mest v Ljubljanski mestni regiji. Geografija Ljubljane, 2002, Ljubljana, s. 215 - 233.

Kinkel, O., 1999: Spilover - Efekte teil der Stadt - Umland - Problematik am Beispiel der Stadt Frankfurt am Main und ihres “Späckgürtels". Dela 14, Ljubljana, s. 209 - 220.

Rus, A., Stanič, I, 1993: Členitev mesta Ljubljane, Urbanistični inštitut R Slovenije.

Rus, A., Stanič, I., 2000: Notranja členitev Ljubljane in njeno povezovanje z urbano regijo. Ljubljana - geografija mesta, Ljubljana, s. $267-276$.

Sić, M., 2004: Role of the Railway-station Zones in the Spatio - functional Development. Geografska problematika Ljubljane in Zagreba, Dela 22, s.67 - 76.

Statistični letopis Ljubljane 2004, MOL - Center za informatiko, Služba za mestno statistiko in analizo.

Prostorski plan Mestne občine Ljubljana: Prostorska zasnova - Povzetek, MOL (2002).

Prostorski plan Mestne občine Ljubljana: Prostorska zasnova, MOL (2002).

Trajnostni razvoj Mestne občine Ljubljana: Strategija (2002), MOL - Oddelek za urbanizem.

Venturi, M., 2002: Postevropsko mesto v Evropi. Urbani Izziv 2002, 1. 13, 2, Ljubljana, s. $5-10$. 
Vrišer, I., 1964: Geografska izhodišča pri omejevanju mest in njihovih vplivnih območij, Urbanistični inštitut LR Slovenije. Ljubljana.

Zakon o urejanju prostora (ZUreP-1), Uradni list R Slovenije 110/2002.

\title{
PROBLEMS OF URBAN DEVELOPMENT AND OF CHANGING OF THE URBAN LAND USE
}

\begin{abstract}
Summary
Disparity between the implementation of the urban plan and reality results in Ljubljana in great pressure put on building areas. The use of the city space is becoming increasingly heterogeneous, being in the light of functional, morphological and social aspect. Such heterogeneity is even increasing on account of extraordinary high prices of land and building, which are still rising. Social segregation is deepening, however "slamisation" of old blocks of flats is hindered by high demand for flats. Also the events of overtaking by investitors and speculations with space are known. The latter is often associated with denationalisation beneficiaries. Infrastructure of the city is also one of the problems.

Numerous new activities of different kinds are not intended for local inhabitants but to those of a wider city or even out-of-the-city space. Besides the growing of big shopping centres at the periphery, a number of smaller concentrations of various activities emerge, considered as a kind of secondary centres. These may include also smaller shopping centres of supply character as well as individual big shopping objects, which are, as a result of increased competition, subject to very different development trends. However, this finally results in the mixed use of space, which is often questionable in the light of functionality, quality of residential environment and also wise development of urban territory. The situation is similar in the periphery, where spatially connected suburbanisation of residing and workplaces is more and more presented.
\end{abstract}

